\title{
IoT Based Power Theft Detection and Monitoring System
}

\author{
N Kunan ${ }^{1}$, Poornima BK ${ }^{2}$ \\ PG Student, Department of Electronics and Communication, Dayananda Sagar University, Bangalore, India ${ }^{1}$ \\ Assistant Professor, Department of Electronics and Communication, Dayananda Sagar University, Bangalore, India ${ }^{2}$
}

\begin{abstract}
Electricity theft is a major concern for the utilities. Many times power theft has been major impact on the economy as well as the development of the country. At present to monitor the various parameters like power consumption, the amount of load and to prevent electricity siphoning, an intelligent device would come handy to solve the problem for the power company and the clients. Application of techniques of power monitoring allows to power monitoring systems to receive the information remotely and in relation to the coordinates and time. In this project we are using smart power meter which are fitted on both at the transmission and load side. These meters are capable of measuring power sent over the load sand power consumed by the load over the time respectively. Both the parameters are sent to the base station wirelessly. Whenever there is a mismatch above the tolerance level parameters, then power theft is detected. The system will trigger the alarm to intimate to the concern authority so that they take necessary legal action and prevent power theft in the future.
\end{abstract}

Keywords: Power Theft, IoT, Web Server, Arduino, Beaglebone Black.

\section{INTRODUCTION}

Application of techniques of power monitoring allows to power monitoring systems to receive the information remotely and in relation to the coordinates and time. In this project we are using smart power meter which are fitted on both at the transmission and load side. These meters are capable of measuring power sent over the load sand power consumed by the load over the time respectively. Both the parameters are sent to the base station wirelessly. Whenever there is a mismatch above the tolerance level parameters, then power theft is detected. The system will trigger the alarm to intimate to the concern authority so that they take necessary legal action and prevent power theft in the future.

\section{LITERATURE SURVEY}

There are two types of power losses, technical losses and non-technical losses. Technical losses are naturally occurring losses due to power dissipation, for example I2R and copper losses. Non - technical losses are due to component break down and electricity theft. Component break down is due to environmental factors and weather conditions such as heavy rains. In [1] the power theft practices are meter tampering, illegal connection, billing irregularities and unpaid bills. There have been various discussions on how to detect and prevent the power theft. [2] Proposes a system design which incorporates an android application and also indicates the exact zone on which unauthorized taping is done in the real time. It would provide a digital record in case of any judicial dispute current. If the line current is greater than the meter then an alert message is sent to the concerned authority with the help of GSM System.

\section{III.SYSTEM IMPLEMENTATION}

The system is a prototype implemented for both transmission line and distribution. Therefore to measure the power we need current and voltage from the mains supply. The voltage is measured from the lines passing through the step down transformer and a voltage regulator so that it gives the regulated dc output that is in the acceptable range of the microcontroller. We also measure the current consumed by the load simultaneously, using a current sensor acs712.Two100 watt bulbs are used for demonstration, considering them as load. Using the above parameters, the instantaneous power and apparent power are calculated. These values are displayed on the serial monitor. These parameters from the transmission lines and distribution lines are uploaded to the web server for remote monitoring. When an undetected load is attached to the system, the actual losses increase.

\section{Methodology}

The method includes sending the power delivered across the line and measured power at the distribution end, determining the difference as in equation (1). If the difference Power loss is greater than some predetermined value 


\section{IJIREEICE \\ Vol. 5, Issue 5, May 2017}

which is the technical loss, then some discrepancies are indicated and it is notified to the authority. An on - going theft case will lead to an increase in the current. Sending the live data from monitoring system to the web server is done using GPRS module.

Power loss = Power Source - Power load- (1)

Power Source-Power delivered across the line

Power Load - Power calculated at the distribution

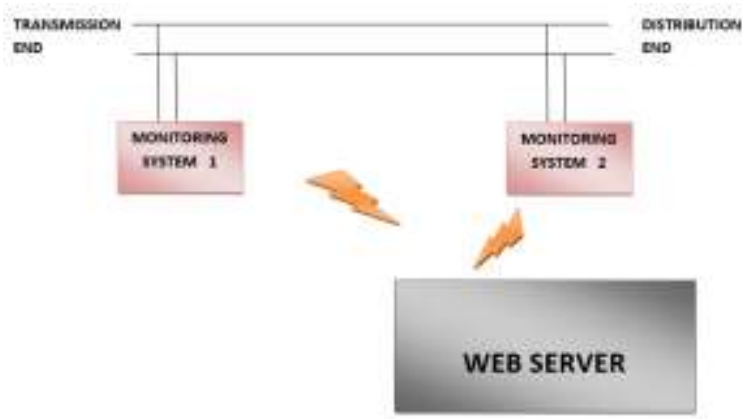

Fig 1 Top level system design

The block diagram of the power monitoring systems are as shown below:

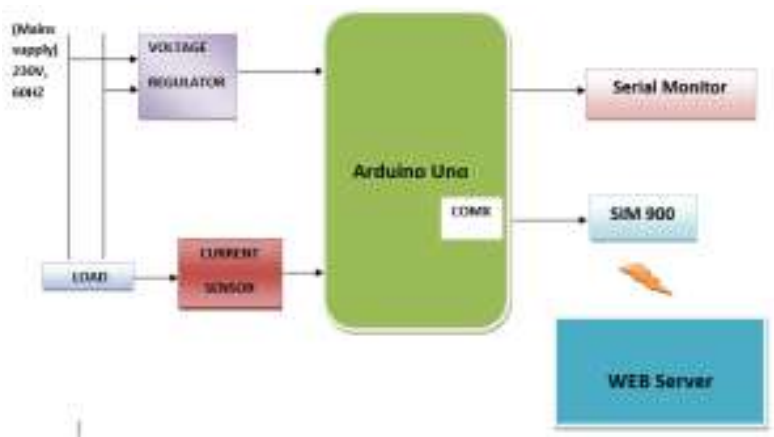

Fig 2 Block diagram of the power monitoring systems

\section{IV.WEB SERVER}

A web server is created using Beaglebone. The scripting languages used are php and html scripting language for creating the webpage and apache2 for running a web server. MYSQL database is used for storing the data live. The calculation process at (1) is carried out at the server side. Also, sending notification is also carried out at this end.
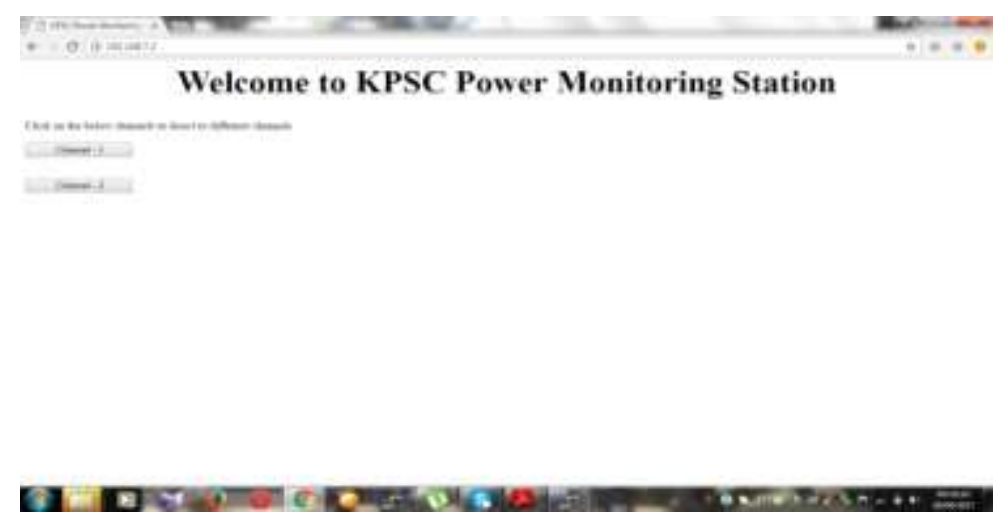

Fig 3 Power monitoring web page

Fig 3 shows the web page of the power theft detection and monitoring system. There are two channels, each channels considered to be a locality or area where power consumption is to be monitored. When we click on the particular channel to be monitored, we can the total power sent over the line and the power sent from each legal consumer. The 
difference would be greater than zero or some tolerance level set as technical loss whenever there is tapping or the illegal connection in the distribution line, Fig 4.

\begin{tabular}{|c|c|c|c|c|}
\hline \multicolumn{5}{|c|}{ Connection succesfiull } \\
\hline Si No & Date Time & Total Power & Lezal Power Received & Tolerance \\
\hline 92 & $2017-05-16 \quad 16: 54: 03$ & 385.11 & 27095 & 114.16 \\
\hline 91 & $2017-05-1616-53.49$ & $2 \longdiv { 3 8 3 2 7 }$ & 26429 & 11898 \\
\hline 90 & $2017-05-16 \quad 16: 53: 35$ & 390.86 & 256.82 & 134.04 \\
\hline 59 & $2017.05 \cdot 16 \quad 16-53: 20$ & 903.40 & 268.63 & 134.77 \\
\hline 88 & $2017-05-16 \quad 16: 53: 05$ & 3370.72 & 269,36 & 10136 \\
\hline 87 & $2017-05-16 \quad 1652.51$ & 37600 & 265.20 & 11080 \\
\hline 86 & $2017-05-16 \quad 16: 52: 41$ & 390.76 & 264.87 & 125.89 \\
\hline 85 & $2017-05-16 \quad 16-52 \cdot 23$ & 3379.47 & 27259 & 10688 \\
\hline 84 & $2017-05-16 \quad 1652,07$ & 39093 & 26302 & 12791 \\
\hline 83 & $2017-05-161651-56$ & $3 \longdiv { 3 7 8 2 9 }$ & 26436 & 113.93 \\
\hline
\end{tabular}

Fig 4: Comparison Table for power data

\section{ADVANTAGES}

Considering current economic issue on the power/ electricity theft this system provides a secure way of monitoring the power across the line. The data from both the monitoring system would be sent to the server at every regular interval. The authority can have continuous access to the data on the power delivered over the time and the received power at load side remotely.

\section{VI.FUTURE SCOPE}

The system can be improved further by a camera module at every fixed distance at the power line such that the monitoring authority can locate the illegal tapping of the power line and take further action.

\section{ACKNOWLEDGMENT}

I would like to express my hearty gratitude to my guide Ms. Poornima BK for giving me constant guidance and encouragement in carrying out the project. I would also like to like thank my friends Chethan BN, SuvidhaBiradar, PramalTekade and Fiaz Habib for their timely and sheer support in making this project a success.

\section{REFERENCES}

[1] Solomon Nunoo, Joseph c. Attachie

[2] A methodology for the design of an electricity theft monitoring system

[3] "Journal of theoretical and Applied Information Technology" April 2011 Vol 26.2 E-ISSN: 1817-3195

[4] Manojkumar M. Patole, Prasanna R. Mane,ShaktiLohar, SnehaSadalagi, Prof.ChandrakantUmarani "GSM Based Power Theft Detection System Using Android" IJESC Vol 6 Issue 5, ISSN: 23213361 C 2016 IJESC

[5] R.Sathish, Elumali C, G Ramkrishnaprabhu, "Power Theft Detection and Information Passing System", International Journal of Advanced Research in Electrical, Electronics and Instrumentation Engineering (IJAREEIE), Vol. 5, Issue 6, June 2016

\section{BIOGRAPHIES}

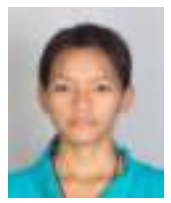

N Kunan PG Student She has completed her BTech in Electronics and Communication from Siddaganga Institute of Technology, Tumkur. She has one year of industry experience from TCS. She is currently pursuing Mtech in Embedded Systems from Dayananda Sagar University, Bangalore.

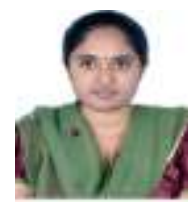

Poornima BK Assistant Professor She has completed her M.Tech in VLSI design and Embedded Systems from JSSATE, Bangalore. Her areas of expertise are ARM microcontrollers, Real Time Embedded Systems and Internet of things (IOT). She has over 3 years of industrial experience. She has worked as a product development engineer for Prolabs and as an Embedded Software Developer for Vestechno solutions and HED Experts Pvt Ltd. She has good working experience in Fire alarm panels'development, Home automation and Automotive Software Industry. she has presented and published papers in 2 National Conferences . 